\title{
Conference Report \\ The 46th EUCHEM Conference on Stereochemistry (Bürgenstock Conference 2011), Brunnen, May 1-6, 2011
}

\section{Leonard J. Prins ${ }^{\star a}$ and Ryan Gilmour ${ }^{\star b}$}

${ }^{*}$ Correspondence: Prof. Dr. L. J. Prinsa ${ }^{a}$, Prof. Dr. R. Gilmourb, aDepartment of Chemical Sciences, University of Padova, Via Marzolo 1, 35131 Padova, Italy Tel. +39049 8275256, E-mail: leonard.prins@unipd.it

'Laboratorium für Organische Chemie, Departement Chemie und Angewandte Biowissenschaften, ETH Zürich, Wolfgang-Pauli-Str. 10, CH-8093 Zürich

Tel. +41 4463279 34, E-mail: ryan.gilmour@org.chem.ethz.ch

Keywords: Bürgenstock conference · EUCHEMS ·

Stereochemistry

For the third consecutive year, the legendary Bürgenstock Conference was held at the picturesque Seehotel Waldstätterhof in Brunnen. It is hardly surprising that the honeymoon venue of the former British Prime Minister Winston Churchill provided a magnificent backdrop for a week of excellent science!

This year the conference was presided over by Jeremy $\boldsymbol{K}$. Sanders (University of Cambridge) who compiled a spectacularly diverse line up of speakers, all of whom are at the cutting edge of their respective disciplines. The organising committee of Donald Hilvert (ETH Zurich), Jérôme Lacour (University of Geneva), Reto Naef (Novartis Pharma), Philippe Renaud (University of Bern), Jay Siegel (University of Zurich) and Helma Wennemers (University of Basel) are to be applauded for their role in assembling delegates from industry and academia in this truly unique setting to discuss the latest trends in chemistry.

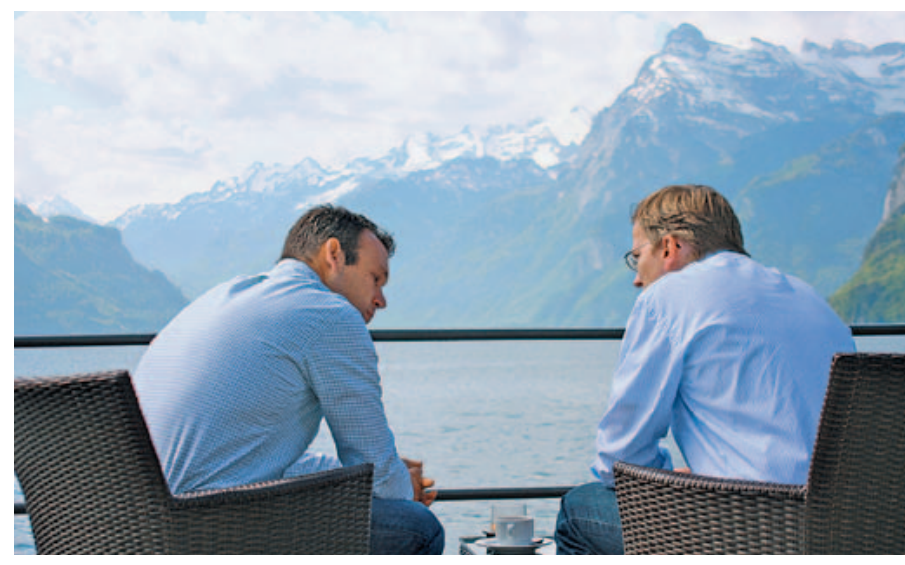

It's a hard life being a chemist.

Following a magnificent welcome dinner on Sunday evening, the president, Jeremy Sanders payed tribute to Dudley Williams in his opening address. Dudley Williams, emeritus professor at the University of Cambridge, had been scheduled to attend the meeting as a guest of honour but sadly passed away in November of last year. His profound scientific influence on a number of the conference speakers was evident, none more so than the first.
With moderator Tom Fyles (University of Victoria) in the chair, Shankar Balasubramanian (University of Cambridge) had the honour of giving the opening lecture of the conference entitled 'Sequencing Nucleic Acids: A Passage from Chemistry to Science and Medicine' which he dedicated to Dudley Williams. In a captivating lecture, the challenges of affordable human genome sequencing were outlined

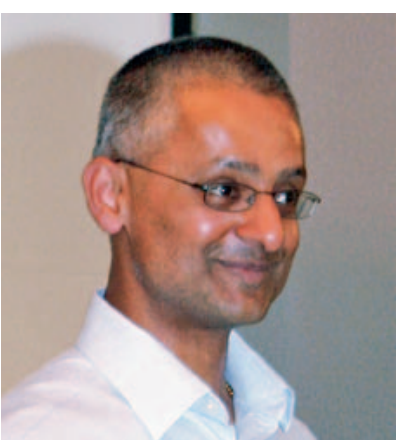

Shankar Balasubramanian together with the implications of this technology on clinical decision making. The founding principles, design process and ultimately the genesis of Solexa sequencing were discussed. This lecture beautifully demonstrated how a chemistry-based application will revolutionize society in the next decade. The potential implications of this technology emerged from a vivid discussion that followed the lecture and continued in the bar for many hours!

Under the moderation of former Bürgenstock president $E$. Peter Kündig (University of Geneva), Monday's morning session proved to be a tour de force of complex molecule synthesis. The first lecture by Karl Gademann (University of Basel) entitled 'Controlling biological processes by truncated natural products' was an exciting fusion of natural product isolation, synthesis, and modification. The chromophore

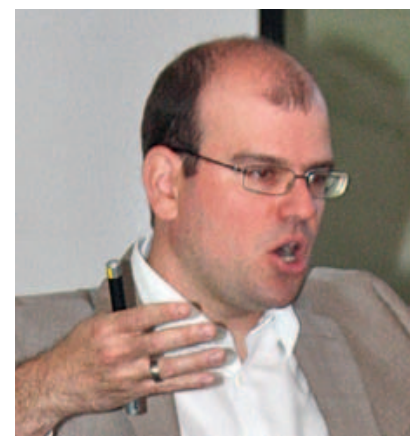

Karl Gademann of the iron chelator anachalin, a molecule that has become the signature of the Gademann group, was highlighted in its role as a constituent of biofilms. Bio-inspired immobilisation strategies were disclosed culminating in the development of functional biomaterials such as PEG-vancomycin as an antibiotic surface. In an action-packed 60 minutes there was even time to disclose the group's total syntheses of numerous anguinomycins with a view to controlling cellular protein transport, and the stereoselective total syntheses of pyridine alkaloids in order to evaluate their neuritogenic activity. In particular, the potential impact of Gademann's research in the world-wide fight against MRSA in hospitals fuelled a lively postlecture dialogue.

The next speaker, Mohammad Movassaghi (MIT), continued the theme of alkaloid chemistry in a breathtaking lecture beginning with the structurally formidable epipolythiodiketopiperazines. Following a com-

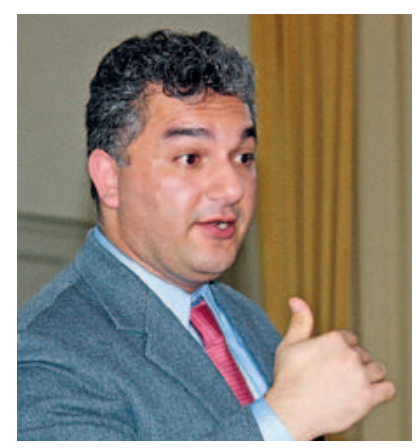

Mohammad Movassaghi 
prehensive, historic overview of the oxidative dimerisation of tryptamine derivatives, the lecture evolved into a master class in cobalt-catalysed radical dimerisations as a strategy to construct a plethora of challenging alkaloids. Other highlights of the lecture included the total syntheses of all known agelastatin alkaloids, containing a 1.4 gram batch enantioselective synthesis of (-)-agelastatin A, and a powerful strategy for the construction of the formidable galbulima alkaloid (-)-himandrine. Following this exciting overview of complex alkaloid synthesis, a number of short ( $8 \mathrm{~min}$ !) poster session appetisers were presented under the watchful eye of Helma Wennemers (University of Basel). Contributors included Ashraf Brik (Ben-Gurion University), Ryan Gilmour (ETH Zurich), Rebecca Goss (University of East Anglia), María Paz Muñoz (IQOG-CSIC, Madrid) and Leonard Prins (University of Padova).

The evening session, opened by Ehud Keinan (Technion), featured a most illuminating lecture by Alanna Schepartz (Yale University) entitled 'Exploring sophisticated protein function with small molecules'. Posing the thought-provoking question, "can $\beta$-peptides support the sophisticated form and function of natural proteins?", the lecture went on to discuss the benefits of protein design without $\alpha$-amino acids. It was beautifully demon-

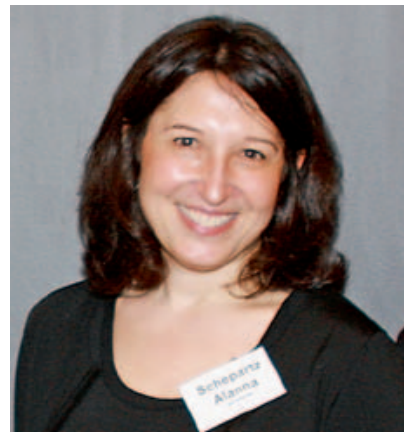

Alanna Schepartz strated that $\beta$-peptide bundles with fluorous cores constitute an important step in the development of an orthogonal protein ensemble, representing the first example of a globular synthetic protein. Exciting applications of the assembly such as its sequestering in an interstitial membrane environment were discussed together with challenges such as the potential synthesis of these orthogonal structures exploiting biological machinery.

Under the moderation of $G e$ bhard Haberhauer (Universität Duisburg-Essen) Tuesday's programme kicked off with a breathtaking lecture from Jason Chin (MRC Cambridge) entitled 'Reprogramming the genetic code'. Such a grand title raises all sorts of expectations; this lecture did not disappoint! Chin's convincing arguments as to the benefits of reprogramming protein translation were compelling, and

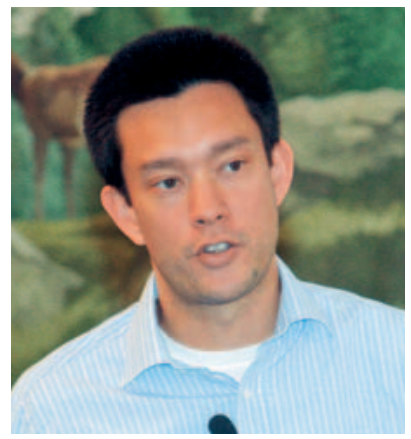
Jason Chin grounded in a desire to evolve and synthesise new function. Lecture highlights included an overview of his group's systematic expansion of the eukaryotic genetic code, the expansion and evolution of the ribosome and efforts to decipher the role of post-translational modifications in regulating organismal function. Chin then illustrated the application of this orthogonal machinery for the in vivo study of protein networks. In particular, the selective photoactivation of a key passage in the MAPKK signalling pathway provided a wonderful new insight into the regulatory mechanisms used by Nature.

The second lecture of this session was given by John Robinson (University of Zurich) who discussed his group's elegant use of protein epitope mimetics as anti-infective agents. Having surveyed the design of $\beta$-hairpin mimetics, synthetic virus-like particles and the exploration of molecular space, he demonstrat- ed how this expertise is being directly applied to the development of HIV vaccines. Importantly, the application of synthetic viruslike particles (SVLPs) was demonstrated for drug delivery, and preliminary HIV neutralising activity in rabbit sera was presented. Much of this incredible technology is now being developed further by the spin-off company Virometix based in Zurich. Additional themes of this high impact lecture included his group's seminal work on using peptidomimetics to explore molecular space, and in particular to probe protein-RNA interactions.

The after-dinner session, chaired by Helma Wennemers (Univeristy of Basel), focussed on a very different aspect of peptide chemistry, namely catalysis. Scott Miller (Yale University) gave a captivating overview of his group's recent achievements in the arena of peptide catalysis; a field that his group continues to lead. Quoting the famous Nature essay by Knowles 'Enzymatic Catalysis: Not Different, Just

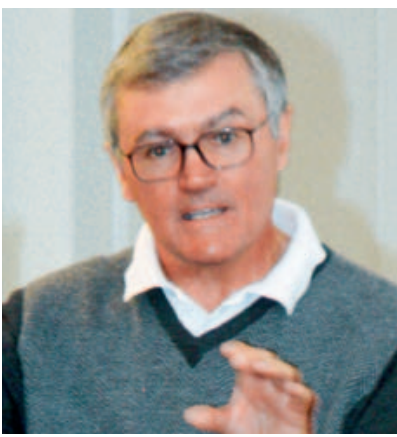

John Robinson Better!', Miller went on to dem-

onstrate that enzyme 'mimics' can be synthesised that expand the capabilities of traditional biosynthetic pathways. Following a scholarly introduction that surveyed numerous amino acidand peptide-catalysed transformations (e.g. his group's asymmetric cysteine-catalysed Rauhut-Currier reaction), Miller went on to describe the utility of aspartate-based catalysts for enantioselective catalysis. A particular highlight of this splendid lecture was the group's recent work on the site-selective modification of complex natural products such as vancomycin and apoptolidin. One concluding remark in particular had particular resonance with a number of participants; "Complex molecule modification is a frontier for chemical catalysis".

The Wednesday morning session was chaired by next years Bürgenstock President, Andreas Pfaltz (University of Basel), who presided over two particularly exciting metal catalysis lectures. The first of these highly topical overviews was given by Melanie Sandford (University of Michigan) who examined the role of high oxidation state metals in $\mathrm{C}-\mathrm{H}$ functionalisation. Didactically, this was a brilliant lecture

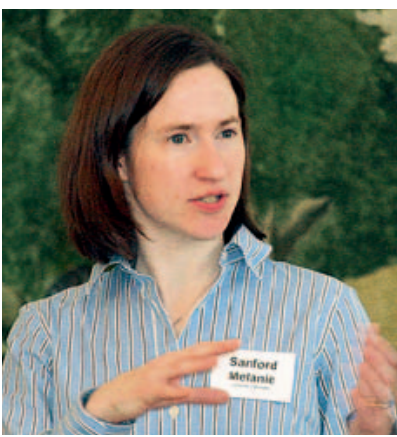

Melanie Sandford thoughtfully guiding the audi-

ence through the early work of Crabtree and others to the latest challenges facing her group. Solutions to the problems of identifying a suitable oxidant, achieving selectivity without directing groups and harnessing the reactivity of high valent palladium to enable novel modes of reactivity were presented. In keeping with the rules of the Bürgenstock meetings, a large proportion of the work presented in this lecture was unpublished highlighting many of the challenges facing groups actively involved in $\mathrm{C}-\mathrm{H}$ activation chemistry. 
This lecture was immediately followed by Jin-Quan Yu (Scripps) who discussed ' $\mathrm{C}-\mathrm{H}$ activation reactions: Enantioand positional selectivity'. In his wonderfully enthusiastic lecture style, Yu outlined his early ambitions to connect $\mathrm{C}-\mathrm{H}$ activation to cross-coupling and outlined his visions of a catalytic platform that might enable this. The talk then moved to reactivity, substrate scope and aspects of ligand acceleration. In the final section of the lecture the groups technology was beautifully applied in an elegant total synthesis of (-)-lithospermic acid. The strategy exploits a late-stage Pd-catalyzed intermolecular $\mathrm{C}-\mathrm{H}$ olefination, to date the most sophisticated application of arene $\mathrm{C}-\mathrm{H}$ olefination to the synthesis of complex natural products.

Following the gala dinner on Wednesday evening, the organisers invited the Asasello Quartet to give a chamber music concert. In his pre-concert address Jeremy Sanders expressed the importance of music in his life and career, and highlighted the case of Alexander Borodin who is credited with discovering the aldol reaction, yet remains best known as a composer. Appropriately, Borodin's $2^{\text {nd }}$ string quartet appeared in the programme alongside Mozart's string quartet in F major (KV 590) and the Paysages by the Swiss composer Ernest Bloch.

The thursday morning session proved to be a tour de force of nucleic acid chemistry. Under the moderation of Donald Hilvert (ETH Zurich) the first lecture was delivered by Yamuna Krishnan (TIFR, Bangalore) entitled 'Molecular DNA devices in living systems'. Her energetic presentation introduced the area of structural DNA technology relying on the use of small rigid DNA-fragments for the self-as-

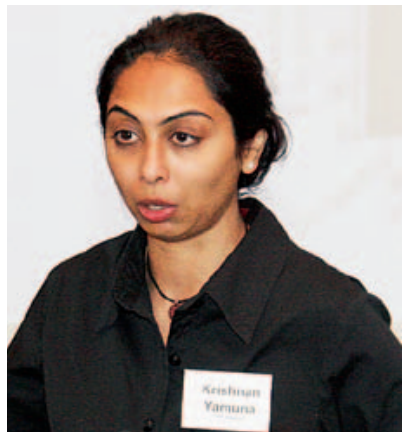

Yamuna Krishnan sembly of large superstructures.

The Krishnan group have cleverly exploited the $\mathrm{pH}$-induced structural change in the I-motif to construct a DNA-device able to map spatial and temporal $\mathrm{pH}$ inside living cells. Additional highlights of the lecture included the use of DNA icosahedrons for the encapsulation of $\mathrm{Au}$ nanoparticles and fluorescent biopolymers.

The second lecture, given by Hanadi Sleiman (McGill University), centered around a related aspect of structural DNA technology, but specifically aimed at the use of dynamic 3D DNA structures for the loading and delivery of cargo in biological and materials applications. Following the introductory section of the lecture where the synthetic challenges were outlined, Sleiman posed the question "how can one position components in a

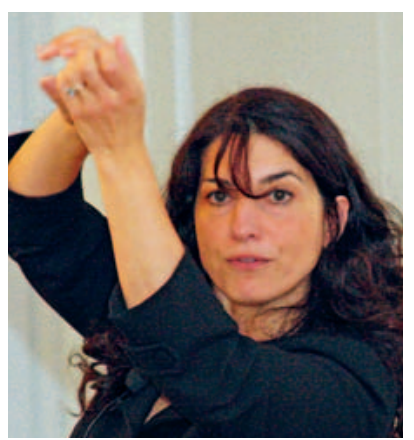

Hanadi Sleiman deliberately designed nanometer scale pattern, be it periodic or aperiodic?" During the remainder of her lecture she presented convincing examples of how DNA assemblies are capable of realising this objective. A beautiful, modular solution was presented in the form of externally controlled dynamic templates giving access to structurally switchable DNA architectures.

The second of the conference poster sessions appetisers saw presentations from Narcis Avarvari (CNRS University of Angers), Takuya Hashimoto (Kyoto University), Alan Rowan (University of Nijmegen), Mark Taylor (University of Toronto) and Jan van Esch (Delft University of Technology). Once again Helma Wennemers was on hand to ensure that everyone stuck to their allocated time.......of exactly 8 minutes!

The Thursday evening lecture was given by Marcel Mayor (University of Basel) with Jan van Esch (Delft University) as moderator. The lecture explored a bottom-up approach to nanotechnology using tailor-made molecules for specific physical experiments. This lecture was unique in the context of the conference programme in that it explored the synergy between synthetic organic chemistry and

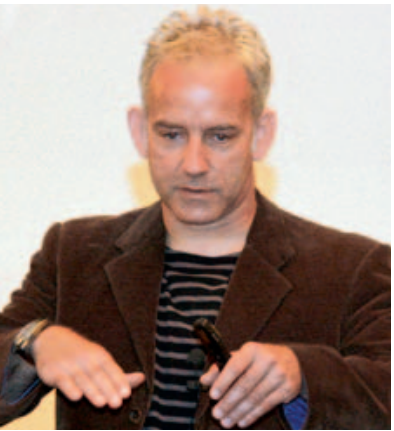
Marcel Mayor physics. Topics included fast temporal fluctuations in single-molecule junctions and optically triggered molecules in a CNT junction. A spectacular section of the talk was dedicated to quantum interference of large organic molecules revealing the quantum wave nature of tailor-made organic molecules in an unprecedented mass and size domain.

The first lecture of the final session on Friday morning was given by Wilhelm Huck (University of Nijmegen) after being introduced by Kay Severin (EPFL). His presentation entitled 'Picoliter droplets as artificial cells' provided a fascinating glimpse into the potential of microfluidics in addressing questions about how the physicochemical environment within cells affects the chemistry of life. In particular, he raised the question "how does

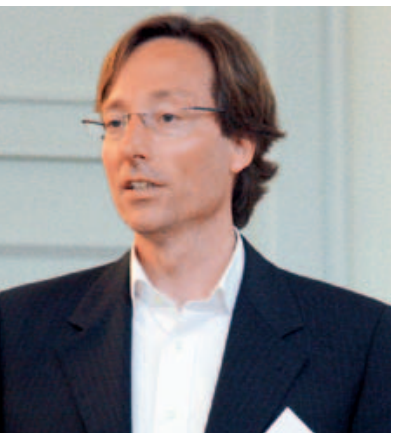

Wilhelm Huck crowdedness in cells alter the kinetics of biological pathways?" Microdroplet technology now allows for the high-throughput study of $20 \mathrm{fL}$ droplets at a frequency of $750 \mathrm{kHz}$. Huck showed that these microdroplets can now be used to systematically study the influence of altered physicochemical parameters on isolated subnetworks.

The conference lecture programme was concluded in spectacular style by Ivan Huc (Bordeaux). His lecture on 'Foldamers: expanding the chemical space' was a firework display of structural complexity. Huc demonstrated that it is possible to control the folding behaviour of oligomers into well-defined three dimensional structures that reach the size of small proteins. Like proteins, foldamers posses a secondary structure which can

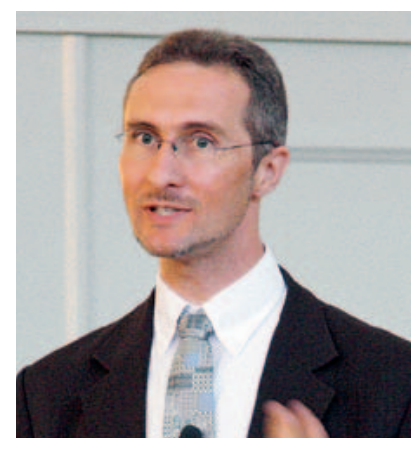

Ivan Huc 
spontaneously aggregate into higher order tertiary structures through helix-helix type interactions. A fascinating molecular shuttle was presented where formation and behaviour relies on different kinetic regimes to modulate shuttling and dissociation. The importance of kinetically controlled processes must be addressed in order to develop molecular machinery for nanotechnological applications.

The Bürgenstock conference remains a highlight in the Swiss academic calendar. The success of this years event is testimony to the vision and efforts of the organising committee and this year's president Jeremy Sanders who have worked tirelessly to deliver an outstanding scientific programme in an awe-inspiring location. We warmly congratulate them and wish next year's President, Andreas Pfaltz, every success. 